\title{
NÍVEIS CRÍTICOS DE FÓSFORO PARA O ESTABELECIMENTO DE GRAMÍNEAS FORRAGEIRAS EM LATOSSOLO VERMELHO-AMARELO, ÁLICO: I: ENSAIO EM CASA DE VEGETAÇÃ̃O ${ }^{1}$
}

\author{
L. de A. CORREA \\ UEPAE de Săo Carlos - EMBRAPA - Caixa Postal, 339 - CEP: 13560-000-São Carlos,SP. \\ H.P. HAAG \\ Prof. Titular do Dep. de Qutmica - ESALQ/USP - Caixa Postal, 9 - CEP: 13418-900-Piracicaba,SP.
}

RESUMO: $\mathbf{O}$ estudo, desenvolvido em casa de vegetação, teve por objetivos determinar os níveis críticos de $\mathbf{P}$ no solo, avaliados pelos extratores de Mehlich I e Resina e na planta, para o estabelecimento das gramíneas Brachiaria decumbens Stapf., Brachiaria brizantha (IIochst.) Stapf. cv. Marandu e Panicum maximum Jacq., em Latossolo Vermelho Amarelo, álico. $O$ delineamento experimental foi o de blocos casualizados com quatro repetiçōes, no esquema fatorial: 7 (doses de P) x 3 (gramíneas). As doses de $P$ corresponderam a $0 ; 17,5 ; 35,0 ; 70,0 ; 140,0 ; 280,0$ e $560,0 \mathrm{ppm}$. Foram realizados dois cortes, o primeiro 50 dias apos a semeadura e o segundo com 30 dias de rebrota. Não foram constatadas diferenças entre as espécies quanto à exigência em $\mathbf{P}$ para o seu estabelecimento. Os níveis críticos de $P$ no solo, para $80 \%$ do crescimento máximo, no primeiro corte, variaram de 8,0 a 12,0 ppm (Mehlich I) e de 13,0 a 18,0 ppm (Resina) para as trés espécies forrageiras. No segundo corte foram de 11,5; 12,0 e 14,0 ppm (Mehlich I) e de 18,0; 22,0 e 24,0 ppm (Resina), para a Brachlaria decumbens, Brachlaria brizantha e Panicum maximum, respectivamente. Os níveis críticos de $P$ na planta foram, na mesma ordem, de 0,11; 0,13 e 0,12\%, no primeiro corte e de 0,09; 0,12 e 0,10\%, no segundo corte.

Descritores: $P$ no solo, P na planta, adubação fosfatada, gramínea forrageira.

\section{CRITICAL LEVELS OF PIOSPIIORUS FOR TIE ESTABLISIIMENT OF PASTURE GRASSES ON A RED YELLOW LATOSOL. I: GREENIIOUSE TEST.}

\begin{abstract}
ARSTRACT: The objectives of the present study, carried out in a greenhouse, were to determine the critical levels of soil P, by the Mehlich I and Resin extractors, and in the plant, for the stablishment of pastures of Brachiaria decumbens Stapf., Brachiaria brizantha (Ilochst.) Stapf cr. Marandu and Panicum maximum JACK., on a Red Yellow Latosol. The experimental design was a randomized complete block with four replications and 21 treatments (7 levels of $P \times 3$ species). The levels of $P$ were: $0 ; 17.5 ; 35.0 ; 70.0 ; 140.0 ; 280.0$ and 560.0 ppm. Two shoot cuts of plants were done: the first, fifty days after sowing and the second, thirty days later. No differences in $\mathbf{P}$ requeriment for crop establishment were observed among the species, for $80 \%$ of maximum growth. The critical level of soil $P$, in the first cut, varied from 8.0 to $12.0 \mathrm{ppm}$ (Mehlich I) and 13.0 to $18.0 \mathrm{ppm}$ (Resin); for the second cut, the levels were 11.5; 12.0 and $14.0 \mathrm{ppm}$ (Mehlich I) and 18.0; 22.0 and $24.0 \mathrm{ppm}$ (Resin), for the Brachiaria decumbens, Brachiaria brizantha and Panicum maximum, respectively. The critical levels of $P$ in the plant were, in the same order, $0.11 ; 0.13$ and $0.12 \%$ for the first cut and $0.09 ; 0.12$ and $0.10 \%$, for the second cut.
\end{abstract}

Key Words: soil phosphorus, plant phosphorus, phosphorus fertilization, grass, pasture.

\section{INTRODUÇÃO}

Os solos brasileiros, entre eles os Latossolos, apresentam deficiência generalizada de fósforo (P). Nesta situação a adubação fosfatada é considerada de vital importância, principalmente na fase de estabelecimento de pastagens. Com o elevado custo dos fertilizantes fosfatados e com as evidências de que as espécies forrageiras apresentam acentuadas variações na exigência em $P$, alguns trabalhos têm sido conduzidos no sentido de determinar o requerimento em $P$ para espécies forrageiras (MARTINEZ \& HAAG, 1980; FONSECA, 1987; GUSS, 1988) para se obter

\footnotetext{
${ }^{1}$ Parte da tese defendida para obtenção do título de Doutor em Agronomia, área de Solos e Nutrição de Plantas da E.S.A. "Luiz de Queiroz"/USP, C.P. 9 - CEP: 13418-900-Piracicaba,SP.
}

Sci. agric., Piracicaba. 50(1):99-108, fev./maio, 1993 
subsídios para uma recomendação mais adequada da adubação. Por outro lado, a exigência em $P$ para uma determinada espécie vegetal varia de solo para solo (REGO et al., 1985; FONSECA, 1987), e os resultados de alguns trabalhos (FONSECA, 1987; GUSS, 1988) que procuraram relacionar características dos solos como teor de argila e com os níveis críticos de $\mathrm{P}$ nos mesmos para as plantas forrageiras, não tem sido satisfatórios, dificultando a extrapolação dos resultados para outros tipos de solo. Portanto, há a necessidade de mais informações sobre os níveis críticos de $\mathrm{P}$ para as plantas forrageiras nos solos tropicais. $O$ presente estudo teve por objetivos estimar os níveis críticos de $\mathbf{P}$ no solo, pelos extratores de Melich I e da Resina e na planta, para o estabclecimento de gramíneas.

\section{MATERIAL E METODOS}

O experimento foi conduzido em casa de vegetação, segundo um esquema fatorial $7 \times 3$ (scte niveis de $\mathrm{P}$ e 3 espécies de forrageiras) em blocos casualizados com quatro repetições. $O$ solo utilizado foi um Latossolo Vermelho Amarelo, álico, da região de São Carlos, Estado de São Paulo, que representa cerca de $22 \%$ da área dos cerrados do País. As características físicas e químicas do solo são: argila $30,7 \%$, silte $13,7 \%$ e areia $55,6 \% ; \mathrm{pH}\left(\mathrm{CaCl}_{2}\right) 4,2 ; \mathrm{Ca}^{2+} 0,33 ; \mathrm{Mg}^{2+}$ 0,$28 ; \mathrm{K}^{+} 0,12 ; \mathrm{H}+\mathrm{Al} 2,5 ; \mathrm{S} 0,7$ e CTC 3,2 $\mathrm{meq} / 100 \mathrm{~cm}^{3}$ e $\mathrm{P} 2,5 \mathrm{ppm}$ (rcsina).

Foram utilizados sacos de polietileno com capacidade de $5 \mathrm{~kg}$ de TFSA. O solo foi colctado na camada de $0-20 \mathrm{~cm}$ de profundidade, que depois de peneirado recebeu calcário dolomítico (PRNT 105\%) na quantidade necessária para clevar a saturação por bases a $55 \%$. Após um periodo de incubação de 30 dias, com umidade em torno de $80 \%$ da capacidade de campo, o solo foi secado, pesado (5 kg de TFSE) e recebeu o $P$ nas doses de $0 ; 17,5 ; 35,0 ; 70,1 ; 140,0 ; 280,0$ e $560,0 \mathrm{ppm}$, em cada vaso, equivalentes, respectivamente a: 0,100 , $200,400,800,1600$ e $3200 \mathrm{~kg}$ de $\mathrm{P} 205 / \mathrm{ha}$, utilizando-se como fonte de $\mathrm{P}$ o superfosfato triplo granulado. Após a homogeneização, foram aplicados também, na forma de solução, 20 ppm de nitrogênio e $2 \mathrm{ppm}$ de zinco em cada vaso, utilizando como fontes o sulfato de amônio $\mathrm{c}$ o sulfato de zinco, respectivamente. As gramíneas utilizadas foram a Brachiaria decumbens Stapf., uma espécie reconhecidamente adaptada às condições de baixa fertilidade de solo e aparentemente com elevada capacidade de absorção e/ou utilização de $\mathrm{P}$; a Brachiaria brizantha (Hochst.) Stapf. cv. Marandu, espécie de introdução relativamente recente no Brasil, que parece scr de maior exigência em fertilidade de solo em relação à Brachiaria decumbens e o Panicum maximum Jacq., que é uma espécie mais exigente em fertilidade do solo, sendo indicado para solos com níveis elevados de fertilidade.

A semeadura das gramíneas foi feita na semana seguinte à aplicação dos tratamentos e 20 dias após foi feito um desbaste deixando-se 10 plantas por vaso. Diariamente foram feitas irrigações, com água proveniente de fonte natural, de tal foram a manter a umidade do solo próxima à capacidade de campo. Semanalmente foram feitas adubações com sulfato de amônio e cloreto de potássio, que totalizaram $150 \mathrm{ppm}$ de $N$ e $150 \mathrm{ppm}$ de $\mathrm{K}_{2} \mathrm{O}$, respectivamente, até cada corte de avaliação. Foram realizados dois cortes a $5 \mathrm{~cm}$ da altura, o primeiro a 50 dias da semeadura, dia 22/11/89, e o segundo com 30 dias de rebrota. Antes de cada corte foi feita a contagem do número de perfilhos em cada vaso. A produção de matéria seca por vaso, em cada corte, foi delerminada pela pesagem da parte aérea, após secagem em estufa à $65^{\circ} \mathrm{C}$ por 48 horas.

Após moagem do material, foi feita a determinação do $P$ na parte aćrea das plantas, por calorimetria, após a digestão nitroperclórica de acordo com SARRUGE \& HAAG (1974). Após o primciro corte foram tiradas 4 subamostras de solo, $\mathrm{cm}$ cada vaso, utilizando-se uma scringa de $12 \mathrm{~cm}$ de comprimentó e $2 \mathrm{~cm}$ de diâmetro, aberta em sua extremidade, que após ser introduzida no solo, teve o seu êmbolo puxado aspirando cada subamostra de solo. Após o segundo corte, o solo de cada vaso foi removido e homogeneizado para se fazer a amostragem. Cada amostra de solo foi analisada e determinado o teor de $\mathrm{P}$ disponível pelo extrator de Mchlich I $\left(\mathrm{H}_{2} \mathrm{SO}_{4} 0.025 \mathrm{~N}+\mathrm{HCl} 0.05 \mathrm{~N}\right)$, na proporção de $10 \mathrm{~cm}^{3}$ de terra para $100 \mathrm{ml}$ de solução cxtratora, segundo o método da EMPRESA BRASILEIRA DE PESQUISA AGROPECUÁRIA (1979), e pelo método da "Resina trocadora de íons", com um tempo de agitação de 16 horas, segundo RAIJ \& QUAGGIO (1983).

Para identificação dos níveis críticos de $P$ no solo foram ajustadas equações de regressão entre o $\mathrm{P}$ aplicado e o $\mathrm{P}$ extraído de cada extrator. A seguir, a produção de matéria seca de cada espécie, foi ajustada a diferentes modelos em função das doses de $P$ aplicadas. Naquelas onde o 
ajuste ao modelo quadrático ou raíz quadrática foi significativo, foi obtida, por derivação, a dose de $P$ responsável pela produção máxima (considerada $100 \%$ ) e a seguir, a responsável por $80 \%$ e $90 \%$ da máxima, ou $80 \%$ e $90 \%$ da produção na maior dose aplicada para os modelos em que as doses estimadas extrapolaram o espaço experimental. Esse valor substituído na equação de regressão entre o P extraído e o $P$ aplicado, forneceu o nível crítico externo de $P$ para cada espécie forrageira em função de cada extrator.

$O$ nível crítico de $P$ na parte aérea foi obtido substituindo o valor da dose de $P$ para $80 \%$ e $90 \%$ da produção máxima, na equação de regressão entre teor de $\mathbf{P}$ na matéria seca $\mathrm{e}$ as doses de $\mathbf{P}$ aplicadas.

Com o propósito de estabilizar as variâncias entre doses, as variáveis teor de $\mathrm{P}$ no solo, teor de $P$ na planta foram transformadas através de logarítmo neperiano e a variável, número de perfilhos foi transformada em $(x)^{1 / 2}$. Quando necessário para interpretação, essas variáveis foram retransformadas para a escala original.

\section{RESULTADOS E DISCUSSÃO}

\section{Produção de matéria seca}

As médias das produções de matéria seca da parte aérea das plantas, são apresentadas na TABELA 1, de acordo com a gramínea, corte e a dose de $P$ aplicada. Verifica-se que as três gramíneas responderam acentuadamenteà adubação fosfatada, sendo a produção de matéria seca muito reduzida na ausência da adubação, para as três espécies, nos dois cortes de avaliação, evidenciando a importância do $P$ neste tipo de solo, para a garantia do estabelecimento dessas forrageiras.

o modelo que melhor se ajustou à produção de matéria seca de cada espécie, em função das doses de $P$ aplicadas, foi o raíz quadrático, cujas equações estão na TABELA 2. Verifica-se que houve uma resposta acentuada na produção de matéria seca com o aumento das doses de $P$ até o equivalente a $800 \mathrm{~kg}$ de $\mathrm{P}_{2} \mathrm{O}_{5} / \mathrm{ha}$ (140ppm) e uma tendência de estabilização na produção nas doses mais elevadas, para as três espécies forrageiras.

As doses críticas de $P$ obtidas através das equações $\mathrm{e}$ as respectivas produções de matéria seca correspondentes a $80 \%$ e $90 \%$ da produção máxima são apresentadas na TABELA 3.

Verifica-se que no primeiro corte de avaliação, o P.maximum foi o mais produtivo, na faixa de $80 \%$ e $90 \%$ da produção máxima, enquanto que a $B$.decumbens apresentou produção próxima à $B$. brizantha. Esse resultado obtido com as duas braquiárias, também foi constatado por GUSS (1988), em estudo em casa de vegetação com cinco Latossolos distintos. No segundo corte, a B.decumbens, devido provavelmente ao seu elevado perfilhamento (Figura 3 ), apresentou maior produção que a B.brizantha, alcançando a do P.maximum.

Quanto às doses críticas de P (TABELA 3), considerando-se os valores para $90 \%$ da produção máxima, pode-se afirmar que estão dentro da faixa citada na literatura, em trabalhos em vasos, em casa de vegetação, que é muito ampla, com valores em torno de $30 \mathrm{ppm}$ (ANDREW \& ROBINS, 1971), $150-400 \mathrm{ppm}$ (REGO et al., 1985; GUSS, 1988), e até 684 ppm de P (FONSECA, 1987).

Verifica-se na TABELA 3 que não ocorreram diferenças $(P>0,05)$ entre as espécies, quanto à dose crítica de $\mathrm{P}$ no solo, no primeiro corte. Esse resultado aparentemente não está de acordo com o fato conhecido da menor exigência $e$ da boa adaptação da B.decumbens, em condições de campo, aos solos de cerrado de baixa fertilidade (ROCHA, 1986; GOMIDE, 1986).

GUSS (1988), trabalhndo em casa de vegetação com cinco latossolos distintos, encontrou valores elevados e equivalência na dose crítica de $P$, no primeiro corte, entre B.decumbens $\mathrm{e}$ B.brizantha, sendo que os valores variaram de 156 ppm a 300 ppm de P, de acordo com os solos. Elevada exigência em $P$ pela $B$.decumbens, em casa de vegetação, também foi constatada por FONSECA (1987).

No segundo corte as doses críticas de $P$ foram ligeiramente mais elevadas que no primeiro, para as três gramíneas (TABELA 3), mostrando a grande dependência das plantas cultivadas em vasos ao $\mathbf{P}$ adicionado. Resultado semelhante foi encontrado por MEIRELLES et al. (1988) trabalhando em vasos, em dois tipos de solo, com o P.maximum (capim-colonião). Por outro lado, FONSECA (1987), trabalhando também em vasos, com três gramíneas, constatou uma diminuição da dose crítica de $P$ no segundo corte, que segundo o autor, foi devida, provavelmente, ao maior desenvolvimento do sistema radicular das plantas. 
TABELA 1. Médias das produções de matéria seca ( $g$ /vaso) da parte aérea das três gramíneas forrageiras, nos cortes 1 e 2 , em resposta as doses de $P$ aplicadas.

Doses de $P$ equivalentes a

\begin{tabular}{|c|c|c|c|c|}
\hline $\mathrm{Kg}$ de $\mathrm{P205} / \mathrm{ha}$ & ppm $\mathbf{P}$ & B.decumbens & B.brizantha & P.maximum \\
\hline & & \multicolumn{3}{|c|}{ corte 1} \\
\hline 0 & 0 & 0,49 & 0,57 & 0,15 \\
\hline 100 & 17,5 & 6,32 & 5,26 & 7,12 \\
\hline 200 & 35,0 & 8,35 & 6,81 & 9,82 \\
\hline 400 & 70,0 & 12,88 & 13,00 & 15,38 \\
\hline 800 & 140,0 & 14,74 & 13,12 & 17,00 \\
\hline 1600 & 280,0 & 12,62 & 13,18 & 17,49 \\
\hline 3200 & 560,0 & 14,39 & $\begin{array}{r}12,73 \\
\text { corte } 2\end{array}$ & 17,10 \\
\hline 0 & 0 & 0,62 & 1,00 & 0,51 \\
\hline 100 & 17,5 & 9,15 & 7,97 & 7,15 \\
\hline 200 & 35,0 & 14,38 & 10,50 & 12,00 \\
\hline 400 & 70,0 & 17,00 & 15,25 & 17,00 \\
\hline 800 & 140,0 & 23,50 & 16,80 & 20,18 \\
\hline 1600 & 280,0 & 22,03 & 17,60 & 21,40 \\
\hline 3200 & 560,0 & 24,00 & 18,80 & 22,40 \\
\hline C.V.\% & $\mathrm{Cl}$ - & 25,64 & 24,99 & 21,62 \\
\hline & $\mathrm{C} 2$ - & 18,06 & 13,94 & 18,28 \\
\hline
\end{tabular}

Com relação às diferenças nas doses críticas entre as três espécies, no segundo corte, elas também não foram significativas $(P>0,05)$. Pelos valores das doses críticas há apenas tendência de uma menor exigência da $B$.decumbens e uma maior exigência de $B$.brizantha e principalmente do P.maximum.

\section{Perfilhamento}

A TABELA 4 apresenta as médias do número observado de perfilhos por vaso, de acordo com a espécie, o corte e a dose de $P$ aplicada.

Após a transformação da variável para $(x)^{1 / 2}$, verificou-se que na ausência da adubação fosfatada, o perfilhamento foi muito reduzido para as três espécies forrageiras, nos dois cortes de avaliação, aumentando significativamente $(P<$ $0,01)$ de forma quadrática, em função das doses de $P$ aplicadas (TABELA 5).

Baseado nessas equações, foram estimadas as doses de $\mathrm{P}$ para as três forrageiras, responsáveis por $80 \%$ do perfilhamento máximo por vaso, nos dois cortes de avaliação.

No primeiro corte, as doses de $\mathrm{P}$ (kg de $\mathrm{P}_{2} \mathrm{O}_{5} / \mathrm{ha}$ ) e o número de perfilhos alcançados foi, respectivamente, 1852 e 85 , para a B.decumbens, 1708 e 57 para a B.brizantha e 1831 e 50 , para o 
TABELA 2. Equações de regressão ajustadas para a produção de matéria seca (y) da parte aérea das três gramíneas, nos dois cortes de avaliação, em função das doses ( $k g$ de $\mathrm{P}_{2} \mathrm{O}_{5} / \mathrm{ha}$ ) de $\mathrm{P}$ aplicadas $(\mathrm{x})$.

\begin{tabular}{lll}
\hline Gramíneas & \multicolumn{1}{c}{ Equações $^{3}$} & $\mathrm{R}^{2}$ \\
\hline B.decumbens $^{2}$ & $\mathrm{y}=0,7290+0,6839 \mathrm{x}^{1 / 2}-0,008 \mathrm{x}$ & 0,92 \\
B.decumbens $^{2}$ & $\mathrm{y}=0,6680+1,0879 \mathrm{x}^{1 / 2}-0,012 \mathrm{x}$ & 0,97 \\
B.brizantha $^{1}$ & $\mathrm{y}=0,1745+0,6832 \mathrm{x}^{1 / 2}-0,008 \mathrm{x}$ & 0,93 \\
B.brizantha $^{2}$ & $\mathrm{y}=1,3911+0,7763 \mathrm{x}^{1 / 2}-0,008 \mathrm{x}$ & 0,97 \\
P.maximum $^{2}$ & $\mathrm{y}=0,3057+0,89032 \mathrm{x}^{1 / 2}-0,11 \mathrm{x}$ & 0,97 \\
P.maximum $^{2}$ & $\mathrm{y}=0,0742+0,9888 \mathrm{x}^{1 / 2}-0,11 \mathrm{x}$ & 0,98 \\
\hline \hline
\end{tabular}

$1-1^{\circ}$ corte, $2-2^{\circ}$ corte, $3-(\mathrm{P}<0,01)$.

TABELA 3. Doses críticas de $\mathrm{P}$ e respectivas produções de matéria seca (MS) da parte aérea, correspondentes a $80 \%$ e $90 \%$ da produção máxima, das três gramíneas, nos dois cortes de avaliação.

\begin{tabular}{|c|c|c|c|c|}
\hline \multirow[b]{2}{*}{ Espécie } & \multicolumn{2}{|c|}{ Doses Críticas (ppm) } & \multicolumn{2}{|c|}{ MS (g/vaso) } \\
\hline & $80 \%$ & $90 \%$ & $80 \%$ & $90 \%$ \\
\hline & \multicolumn{4}{|c|}{$1^{\circ}$ Corte } \\
\hline B.decumbens & $94 \mathrm{~A}$ & $149 \mathrm{~A}$ & 12,3 & 13,8 \\
\hline B.brizantha & $91 \mathrm{~A}$ & $140 \mathrm{~A}$ & 11,4 & 13,0 \\
\hline \multirow[t]{2}{*}{ P.maximum } & $92 \mathrm{~A}$ & $140 \mathrm{~A}$ & 15,4 & 17,0 \\
\hline & \multicolumn{4}{|c|}{$2^{\circ}$ Corte } \\
\hline B.decumbens & $102 \mathrm{~A}$ & $157 \mathrm{~A}$ & 19,5 & 22,2 \\
\hline B.brizantha & $110 \mathrm{~A}$ & $172 \mathrm{~A}$ & 15,6 & 17,6 \\
\hline P.maximum & $116 \mathrm{~A}$ & $179 \mathrm{~A}$ & 18,5 & 20,8 \\
\hline
\end{tabular}

Doses críticas dentro de cada corte e de cada porcentagem de produção máxima, com letras indênticas, não diferem entre si $(P>0,05)$

P.maximum e no segundo corte, na mesma ordem, 1779 e 93,1740 e 69 e 1790 e 75 , incluindo as 10 plantas originais.

A B.decumbens foi a espécie que apresentou a maior capacidade de perfilhamento, exceto na ausência da adubação fosfatada, onde as três espécies praticamente não perfilharam (Figura 3). Essa sua elevada capacidade de perfilhamento, é responsável, em parte, pela rapidez de estabelecimento e pela boa cobertura de solo observada para esta espécie, nas mais variadas condições de fertilidade do solo. Sua maior produção de perfilhos em relação à Brachiaria brizantha, também foi constatada por GUSS (1988), em estudo de resposta ao $P$, com quatro espécies do gênero Brachiaria em casa de vegetação. 
TABELA 4 - Médias do número de perfilhos, observados por vaso, de acordo com a espécie, em resposta às doses de $\mathrm{P}$ aplicadas, nos cortes 1 (C1) e 2 (C2).

\begin{tabular}{|c|c|c|c|c|c|c|c|}
\hline \multicolumn{2}{|c|}{ Dose de $\mathrm{P}$ equivalente a } & \multicolumn{2}{|c|}{ B.decumbens } & \multicolumn{2}{|c|}{ B.brizantha } & \multicolumn{2}{|c|}{ P.maximum } \\
\hline $\mathrm{kg} \mathrm{P205/ha}$ & $\mathrm{ppm} \mathbf{P}$ & $\mathrm{Cl}$ & $\mathrm{C} 2$ & $\mathrm{Cl}$ & $\mathrm{C} 2$ & $\mathrm{C} 1$ & $\mathrm{C} 2$ \\
\hline 0 & 0 & 10 & 14 & 10 & 11 & 10 & 12 \\
\hline 100 & 17,5 & 36 & 39 & 20 & 30 & 17 & 21 \\
\hline 200 & 35,0 & 45 & 49 & 24 & 34 & 27 & 34 \\
\hline 400 & 70,0 & 56 & 59 & 35 & 48 & 35 & 43 \\
\hline 430 & 140,0 & 66 & 69 & 43 & 53 & 38 & 53 \\
\hline 1600 & 280,0 & 63 & 76 & 46 & 56 & 41 & 59 \\
\hline 3200 & 560,0 & 75 & 85 & 45 & 59 & 44 & 69 \\
\hline C.V. $\%$ & & 21,5 & 17,9 & 17,6 & 18,3 & 17,2 & 18,3 \\
\hline
\end{tabular}

TABELA 5 - Equações de regressão ajustadas para o número de perfillos por vaso, transformados para $(x)^{1 / 2}$, $\mathrm{cm}$ função das doses de $\mathrm{P}$ aplicadas, nos dois cortes de avaliação das três gramíneas

\begin{tabular}{lll}
\hline \hline Gramineas & \multicolumn{1}{c}{ Equações $^{3}$} & $\mathrm{R}^{2}$ \\
\hline B.decumbens $^{1}$ & $\mathrm{y}=5,1496+0,00370473 \mathrm{x}-0,00000083 \mathrm{x}^{2}$ & 0,65 \\
B.decumbens $^{2}$ & $\mathrm{y}=5,4093+0,00400387 \mathrm{x}-0,00000089 \mathrm{x}^{2}$ & 0,73 \\
B.brizantha $^{1}$ & $\mathrm{y}=4,0613+0,00341608 \mathrm{x}-0,00000082 \mathrm{x}^{2}$ & 0,83 \\
B.brizantha $^{2}$ & $\mathrm{y}=4,7600+0,00348107 \mathrm{x}-0,00000081 \mathrm{x}^{2}$ & 0,71 \\
P.maximum $^{1}$ & $\mathrm{y}=4,0903+0,00289752 \mathrm{x}-0,00000067 \mathrm{x}^{2}$ & 0,76 \\
P.maximum $^{2}$ & $\mathrm{y}=4,3554+0,00402737 \mathrm{x}-0,00000088 \mathrm{x}^{2}$ & 0,86 \\
\hline \hline
\end{tabular}

$1-1^{\circ}$ conte, $2-2^{\circ}$ corte, $3-(\mathrm{P}<0,01)$.

Segundo o autor, cssas diferenças no perfilhamento podem significar necessidades de densidades de semeaduras distintas entre as cspécies, para se promover igual cobertura de solo, em determinado período.

\section{Níveis críticos de P na planta}

Os teores de P na matéria seca da parte aćrca das três gramíncas aumentaram significativamente $(P<0,01)$ com o aumento das doses de $\mathbf{P}$ aplicadas, sendo que os dados ajustaram=se a modelos lincares e quadráticos (TABELA 6)

Verifica-se, nas Figuras 4 c 5 , um acúmulo de $\mathrm{P}$ para as três gramíneas forrageiras, à medida que se aumentou o $\mathrm{P}$ aplicado, sendo que o acúmulo foi mais accntuado para a Brachiaria brizantha e o Panicum maximum e menos para a Brachiaria decumbens, fato esse que refletiu diretamente nos níveis críticos internos de $P$ (TABELA 7).

Considerando a porcentagem de $P$ na parte aérea associada a $90 \%$ da produção máxima (TABELA 7), verifica-se que os teores estão dentro 
TABELA 6 - Equações de regressão ajustadas para os teores de P na parte aérea das três gramíneas, transformado para $1 n(x)$, nos dois cortes, em função das doses de $P$ aplicadas.

\begin{tabular}{lll}
\hline \hline Gramíneas & \multicolumn{1}{c}{ Equações $^{3}$} & $\mathrm{R}^{2}$ \\
\hline B.decumbens $^{2}$ & $\mathrm{y}=-2,3882+0,000339 \mathrm{x}$ & 0,83 \\
B.decumbens $^{2}$ & $\mathrm{y}=-2,5855+0,000350 \mathrm{x}$ & 0,92 \\
B.brizantha $^{1}$ & $\mathrm{y}=-2,5052+0,000943 \mathrm{x}-0,00000015 \mathrm{x}^{2}$ & 0,99 \\
B.brizantha $^{2}$ & $\mathrm{y}=-2,8040+0,001242 \mathrm{x}-0,00000023 \mathrm{x}^{2}$ & 0,98 \\
P.maximum $^{2}$ & $\mathrm{y}=-2,6192+0,001030 \mathrm{x}-0,00000019 \mathrm{x}^{2}$ & 0,93 \\
P.maximum $^{2}$ & $\mathrm{y}=-2,9291+0,001132 \mathrm{x}-0,00000020 \mathrm{x}^{2}$ & 0,98 \\
\hline \hline
\end{tabular}

$1-1^{\circ}$ corte, $2-2^{\circ}$ corte, $3-(\mathrm{P}<0,01)$.

da ampla faixa de valores encontrados na literatura, em trabalhos em vasos, em casa de vegetação (REGO et al., 1985; GUSS, 1988; FONSECA, 1987). Quanto às diferenças nos níveis críticos de $P$ entre as espécies, associadas a $80 \%$ da produção máxima (TABELA 7), elas não são tão acentuadas, da mesma forma que ocorreu com as doses críticas de $\mathbf{P}$ no solo (TABELA 3). Todavia, observa-se, nos dois cortes, valores inferiores para a Brachiaria decumbens e valores mais elevados para o Panicum maximum e, principalmente, para a Brachiaria brizantha. GUSS (1988), trabalhando em vasos, com cinco Latossolos, não encontrou diferenças no nível crítico interno de $\mathrm{P}$ entre a Brachiaria brizantha e a Brachiaria decumbens, associado a $90 \%$ da produção máxima.

\section{Níveis críticos de $\mathbf{P}$ no solo}

De maneira geral, os níveis críticos de $\mathrm{P}$ no solo (TABELA 8) obtidos pelo método da Resina, foram superiores aos obtidos pelo método de Mehlich I, evidenciando a sua maior capacidade de extração do $P$ adicionado neste tipo de solo.

Devido à grande variação ocorrida dentro de repetições, nos resultados da análise de $P$ no solo, no primeiro corte, pode-se dizer que as diferenças observadas entre as gramíneas, quanto ao nível crítico (TABELA 8), são variaçōes devido apenas à falhas na amostragem preconizada. Provavelmente as quatro subamostras retiradas por vaso não foram suficientes. $\mathrm{Na}$ realidade essas diferenças não têm razão de existir, se levar-se em conta que a dose crítica de $P$ foi a mesma no primeiro corte (TABELA 3) e o P extraído pelas plantas semelhantes e muito pouco em relação ao aplicado. Baseado nestes fatos, conclui-se que as três espécies apresentaram o mesmo requerimento de $P$ no primeiro corte. Este resultado aparentemente não está de acordo com observações de campo, que indicam a menor exigência da Brachiaria decumbens, em relação à maioria das gramíneras forrageiras tropicais (CENTRO INTERNACIONAL DE AGRICULTURA TROPICAL, 1978; GOMIDE, 1986).

GUSS (1988), em estudo em vasos, também encontrou o mesmo nível crítico de $P$ no solo para a B.brizantha e a B.decumbens.

No segundo corte, da mesma maneira que ocorreu com as doses críticas de P., houve apenas tendências de diferenças quanto ao nível crítico de P no solo (TABELA 8). Pelo extrator de Mehlich I, conclui-se pela similaridade no requerimento de P entre a B.decumbens e a B.brizantha e pela tendência de maior exigência do P.maximum. Essa semelhança no nível crítico pelo extrator de Mehlich I, entre as duas braquiárias, também foi constatada por GUSS (1988). Pelo método da Resina, houve também apenas tendências de discriminar as diferenças de exigência entre as espécies, com indicação de uma menor exigência de B.decumbens e maior exigência da B.brizantha e principalmente do P.maximum (TABELA 8). Embora a Brachiaria decumbens tenha mostrado tendência de uma menor exigência em $P$, no segundo corte, os níveis críticos parecem ser 
TABELA 7 - Níveis críticos de P na matéria seca da parte aérea das três gramíneas nos cortes 1 e 2 , para as produções estimadas de $80 \%$ e $90 \%$ da máxima.

\begin{tabular}{|c|c|c|c|c|}
\hline \multirow{3}{*}{ Espécie } & \multicolumn{2}{|c|}{ Corte 1} & \multicolumn{2}{|c|}{ Corte 2} \\
\hline & \multicolumn{2}{|c|}{ Nível Crítico } & \multicolumn{2}{|c|}{ Nível Crítico } \\
\hline & $80 \%$ & $90 \%$ & $80 \%$ & $90 \%$ \\
\hline B.decumbens & $0,11(11,7)^{*}$ & 0,12 & $0,09(7,0)^{*}$ & 0,10 \\
\hline B.brizantha & $0,13(8,2)$ & 0,16 & $0,12(13,7)$ & 0,16 \\
\hline P.maximum & $0,12(10,8)$ & 0,15 & $0,10(8,0)$ & 0,14 \\
\hline
\end{tabular}

* Coeficiente de variação dos dados transformados.

TABELA 8 - Níveis críticos de P no solo pelos extratores de Mchlich e Resina, associados a $80 \%$ da produção maxima de matéria seca da parte aérea das três gramíneas nos cortes 1 (C1) e 2 (C2).

\begin{tabular}{|c|c|c|c|c|}
\hline \multirow{3}{*}{ Espécie } & \multicolumn{4}{|c|}{ Extratores } \\
\hline & \multicolumn{2}{|c|}{ Mchlich I } & \multicolumn{2}{|c|}{ Resina } \\
\hline & $\mathrm{Cl}$ & $\mathrm{C} 2$ & $\mathrm{C} 1$ & $\mathrm{C} 2$ \\
\hline & * & * & * & * \\
\hline B.decumbens & $12,0(21,0)$ & $11,5(9,7)$ & $18,0(23,2)$ & $18,0(9,4)$ \\
\hline B.brizantha & $8,5(27,6)$ & $12,0(7,7)$ & $15,0(25,8)$ & $22,0(8,4)$ \\
\hline P.maximum & $8,0(20,7)$ & $14,0(10,0)$ & $13,0(25,4)$ & $24,0(10,4)$ \\
\hline
\end{tabular}

* Coeficiente de variação dos dados transformados.

relativamente elevados, por ser esta uma espécie conhecida pela sua baixa exigência $\mathrm{cm} P$ (CENTRO INTERNACIONAL DE AGRICULTURA TROPICAL, 1978; SALINAS \& SANCHEZ, 1976), e ainda por ser uma exigência de $\mathbf{P}$ no segundo corte, quando se esperaria uma diminuição do seu requerimento (ITALIANO ct al., 1981).

Essá baixa discriminação na exigência em $P$ para as gramíneas forrageiras, em ensaios em vasos, em casa de vegetação, assim como a obtenção de níveis críticos de $P$ no solo relativamente elcvados, para espécics que aparentam ser tolerantes à baixa fertilidade, em condições de campo, tem sido constatado também por outros pesquisadores (ANDREW \& ROBINS, 1971; REGO at al., 1985; FONSECA, 1987; GUSS, 1988).

\section{Absorção, uso e quociente de utilização do $P$}

Como as três gramíneas mostraram respostas quadráticas às doses de $\mathrm{P}$ aplicadas $\mathrm{e}$ como na ausência da adubação a produção de 
TABELA 9 - Eficiência de absorção, uso e quociente de utilização do P pelas três grarníneas, nos cortes 1 e 2, com a dose estimada para $80 \%$ da produção máxima de matéria seca (MS) da parte área.

\begin{tabular}{cccc}
\hline \hline Espécie & Eficiência de absorção $^{1}$ & Eficiência de uso $^{2}$ & Quociente de utilização $^{3}$ \\
\hline & & $1^{\circ}$ Corte & \\
B.decumbens & 28,7 & 38,0 & 909 \\
B.brizantha & 32,0 & 40,0 & 769 \\
P.maximum & 40,1 & 30,0 & 833 \\
& & $2^{\circ}$ Corte & \\
B.decumbens & 34,7 & 26,0 & 1113 \\
B.brizantha & 34,0 & 35,0 & 834 \\
P.maximumn & 31,2 & 31,0 & 1000 \\
\hline \hline
\end{tabular}

1 - $\mathrm{mg}$ de $\mathrm{P}$ absorvido por $\mathrm{g}$ de $\mathrm{P}$ aplicado.

2 - $\mathrm{mg}$ de $P$ aplicado por $\mathrm{g}$ de matéria seca produzida.

3 - $g$ de MS produzida por $g$ de $P$ presente na biomassa.

matéria seca foi muito reduzida para as mesmas, nos dois cortes (TABELA 1), optou-se por comparar a eficiência das mesmas apenas na dose onde ocorreria $80 \%$ do crescimento máximo, por estar próximo ao ótimo biológico. Os resultados estão na TABELA 9.

Desde que não houve diferença entre as espécies quando às doses críticas (TABELA 3) e pouca variação quanto aos níveis críticos de $P$ na planta (TABELA 7) e produção de matéria seca (TABELA 3), as diferenças entre as espécies quanto à eficiência de absorção, uso e quociente de utilização do $P$ também não foram acentuadas (TABELA 9).

Verifica-se, apenas no primeiro corte, uma superioridade de Panicum maximum quanto à eficiência de absorção e uso do $\mathrm{P}$ em relação às outras duas espécies. No segundo corte, a eficiência de absorção foi praticamente igual para as três espécies e quanto à eficiência do uso de $P$, ocorreu uma superioridade da Brachiaria decumbens, principalmente em relação a Brachiaria brizantha. Para o quociente de utilização do $P$, este foi inferior, no caso da Brachiaria brizantha, nos dois cortes de avaliação.

GUSS (1988), trabalhando em vasos, com cinco Latossolos, não constatou diferenças entre as espécies Brachiaria decumbens e Brachiaria brizantha, quanto à absorção e uso do $\mathrm{P}$, associado a $90 \%$ da produção máxima.

\section{CONCLUSÕES}

Neste estudo em casa de vegetação, não foram constatadas diferenças entre as espécies quanto à exigência em $\mathbf{P}$ para o estabelecimento das gramíneas. Os níveis críticos de $\mathbf{P}$ no solo, para $80 \%$ dos crescimentos máximos, no primeiro corte, variaram de 8,0 a $12,0 \mathrm{ppm}$ pelo extrator de Mehlich I e de 13 a $18 \mathrm{ppm}$ pelo método da Resina, para as três gramíneas forrageiras. No segundo corte foram de 11,$5 ; 12,0$ e 14,0 ppm pelo extrator Mehlich I e de 18,0;22,0 e 24,0 ppm pelo método da Resina, respectivamente, para a Brachiaria decumbens, Brachiaria brizantha e o Panicum maximum. Os niveis críticos de $P$ na planta foram, na mesma ordem, de 0,$11 ; 0,13 \mathrm{e}$ $0,12 \%$, no primeiro corte, e de 0,$09 ; 0,12$ e $0,10 \%$, no segundo corte.

\section{REFERÊNCIAS BIBLIOGRÁFICAS}

ANDREW, C.S.; ROBINS, M.F. The effect of phosphorus on the growth, chemical composition and critical phosphorus percentages of some tropical pasture grasses. Australian Journal Agricultural Research, East Melbourne, v.22, p.693-703, 1971. 
CENTRO INTERNACIONAL DE AGRICULTURA TROPICAL. Nutricion mineral de plantas forrajeras: In: Programa de ganado de corte; informe anual - 1978. Cali : CIAT, 1978. 124p.

EMPRESA BRASILEIRA DE PESQUISA AGROPECUÁRIA. Serviço Nacional de Levantamento e Conservação de Solos. Manual de métodos de análises de solo. Rio de Janeiro : EMBRAPA, SNLCS, 1979, n.p.

FONSECA, D.M. Níveis críticos de Ps em amostras de solos para o estabelecimento de Andropogon gayanus, Brachiaria decumbens e Hyparthenia rufa. Viçosa,

1987. 146p. Dissertação (Mestrado) - Universidade Federal de Viçosa.

GOMIDE, J.A. Exploraçāo de pastagens em solos de baixa fertilidade. In: CONGRESSO DE PASTAGENS; SIMPÓSIO SOBRE MANEJO DA PASTAGEM, 8., 1986, Piracicaba, Anais... Piracicaba : FEALQ, 1986. p.481-497.

GUSS, A. Exigência de fósforo para o estabelecimento de gramineas e leguminosas forrageiras tropicais em solos com diferentes características físicas e químicas. Viçosa, 1988. 74p. Tese (Doutorado) - Universidade Federal de Viçosa).

ITALIANO, E.C.; GOMIDE, J.A.; MONNERAT, P.H. Doses e modalidades de aplicação de superfosfato simples na semeadura do capim-jaraguá. Revista da Sociedade Brasileira de Zootecnia, Viçosa, v.10, p.1-10, 1981 .

MARTINEZ, H.E.P.; HAAG, H.P. Niveis crílicos de fósforo em Brachiaria decumbens (Stapf) Prain, Brachiaria humidicola (Rendle) Schweickerdt, Digitaria decumbens Stent, Hyparrhenia rufa (Ness) Stapf., Melinis minutiflora Pal de Beauv., Panicum maximum Jacq. e Pennisetum purpureum Schum. Anais da Escola Superior de Agricultura "Luiz de Queiroz", Piracicaba, v.37, p.913-977, 1980.
MEIRELLES, N.M.F.; WERNER, J.C.; ABRAMIDES, P.L.G.; CARRIEL, J.M.; PAULINO, V.T.; COLOZZA, M.T. Nivel crítico de fósforo em capimcolonião cultivado em dois tipos de solo: latossolo vermelho escuro e podzólico vermelho amarelo. Boletim de Indústria Animal, Nova Odessa, v.45, n.1, p.215-232. 1988.

RAU, B. van; QUAGGIO, J.A. Metodo de análise de solo para fins de fertilidade. Campinas, Instituto Agronômico, 1983, 31p. (IAC. Boletim, 81).

REGO, M.C.; GOMIDE, J.A.; NOVAIS, R.F. Phosphorus requeriment for grass establishment in five tropical soils. In: INTERNATIONAL GRASSLAND CONGRESS, 15., 1985, Kioto. Proceedings... Kyoto : Science Councill of Japan and Japanese Society of Grassland Science, 1985. p.476-477.

ROCHA, G.L. Perspectivas e problemas de adubação de pastagens no Brasil. In: SIMPÓSIO SOBRE CALAGEM E ADUBAÇÃo DE PASTAGENS, 1 ., 1985, Nova Odessa, Anais... Piracicaba : Associação Brasileira para Pesquisa da Potassa e do Fósforo, 1986. p.1-29.

SALINAS, J.G.; SANCHEZ, P.A. Soil-plant relationships affecting varietal and species differences in tolerance to low available soil phosphorus. Ciencia e Cultura, São Paulo, v.28, n.2, p.156-168, 1976.

SARRUGE, J.R.; HAAG, H.P. Análises químicas em plantas. Piracicaba : ESALQ, Departamento de Química, 1974. 56p.

Trabalho entregue para publicaçāo em 03.10.91

Trabalho aprovado para publicação em 30.09.92 